\title{
Leiomyosarcoma with partial rhabdomyoblastic differentiation: First case report of primary cardiac origin
}

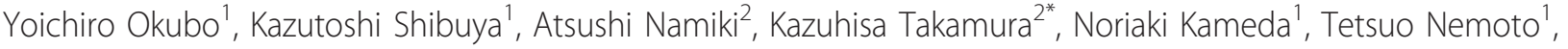 \\ Aki Mitsuda ${ }^{1}$, Megumi Wakayama ${ }^{1}$, Minoru Shinozaki ${ }^{1}$, Nobuyuki Hiruta' ${ }^{1}$ Kanako Kitahara ${ }^{1}$, Takao Ishiwatari ${ }^{1}$, \\ Junichi Yamazaki²
}

\begin{abstract}
Background: Leiomyosarcoma occurring as a primary cardiac tumor has been known as an extremely rare condition. Previous studies of leiomyosarcoma with rhabdomyoblastic differentiation have conducted to those arisen from another site, and they indicated a poorer prognosis of this tumor.

Case presentation: A 69-year-old woman was referred to our hospital for an operation concerning umbilical hernia. Subsequent imaging examinations before an operation indicated the presence of primary cardiac malignant tumor due to its atypical shape. And then, it was surgically removed. Histopathologically, tumor cells consisted of two different types: spindle and polyhedral cells. Immunohistochemically, it is interesting to note that $2.1 \%$ of spindle cells and $23.1 \%$ of polyhedral cells showed positive reactivity for myogenin. Furthermore, we performed double-immunostaining for alpha-smooth muscle actin (SMA) and myogenin. The rates of alpha-SMA and myogenin double negative, alpha-SMA single positive, myogenin single positive, and alpha-SMA and myogenin double positive in spindle cells were estimated as $69.1 \%, 28.8 \%, 1.1 \%$ and $1.0 \%$, respectively. In contrast, the rates in polyhedral cells were estimated as $76.9 \%, 0.0 \%, 23.1 \%$, and $0.0 \%$, respectively.

Conclusion: Our immunohistochemical evaluation suggested that rhabdomyoblastic differentiation in leiomyosarcoma might be generated not only by de novo generation from mesenchymal cells. To the best of our knowledge, this is the first case of primary cardiac leiomyosarcoma with partial rhabdomyoblastic differentiation.
\end{abstract}

\section{Background}

Primary cardiac tumors represent a rare neoplastic condition with an incidence that ranges from 0.0017 to $0.019 \%$ [1], of which $25 \%$ are malignant. Among such tumors, angiosarcoma is the commonest malignant tumor followed by rhabdomyosarcoma, malignant mesothelioma, and fibrosarcoma, each with an incidence that is greater than $10 \%$ [2]. However, the incidence of cardiac leiomyosarcoma is less than 1\% [2]. Previous studies of leiomyosarcoma with rhabdomyoblastic differentiation have conducted to those arisen from another site [3-11], and they announced a poorer prognosis of this tumor.

\footnotetext{
* Correspondence: kazuhisa.t@med.toho-u.ac.jp

${ }^{2}$ Division of Cardiovascular Medicine, Department of Internal Medicine, Toho University Omori Medical Center, Toho University School of Medicine, 6-11-1 Omori-Nishi, Ota-Ku, Tokyo, 143-8541, Japan

Full list of author information is available at the end of the article
}

Especially, Oshiro et al. have reported that leiomyosarcoma with rhabdomyoblastic differentiation shows poorer prognosis than typical leiomyosarcoma [6]. In the present paper, we describe an extremely rare primary cardiac malignant tumor. To the best of our knowledge, this is the first case of primary cardiac leiomyosarcoma with partial rhabdomyoblastic differentiation.

\section{Case presentation}

A 69-year-old woman was referred to our hospital for an operation concerning umbilical hernia who had been diagnosed with hypertension and polycystic kidney disease one year prior to her surgery. Subsequent transthoracic cardiac ultrasonography in our hospital showed a club-shaped tumor of $34 \mathrm{~mm}$ in diameter inside the left atrial cavity in a four-cavities tomogram. Transesophageal cardiac ultrasonography showed a broad-based, 
gigantic, and multilocular tumor occupying almost the entire left atrium (Figure 1). Chest computed tomography (CT) showed no abnormality in the lungs or hilar lymph nodes. Abdominal CT showed multilocular cysts in bilateral kidneys. Cardiac magnetic resonance imaging showed a broad-based protuberant tumor which had a $\mathrm{T} 1$ iso-signal intensity and high T2 signal intensity in the posterior wall of the left atrium. Positron emission tomography analysis showed abnormal 18F- fluorodeoxy glucose uptake which was detected only in the heart, with the exception of the umbilical hernia lesion. These results indicated the presence of primary cardiac malignant tumor due to its atypical shape. Finally, surgical removal with the patient's permission was performed. Almost all of the tumor could be removed and subsequent chemotherapy was considered. However, the patient's renal dysfunction ruined adjuvant chemotherapy and she died of her disease nine months after the surgical removal due to multiple lung metastases.

\section{Pathologic findings}

Macroscopically, the submitted specimen comprised several cakes of the tumor with a gray-white color on the surface (Figure 2). It was fixed with $10 \%$ buffered formalin, embedded in paraffin wax after dehydration, and cut into four $\mu \mathrm{m}$-thick sections. These were then prepared and stained with hematoxylin and eosin (HE) double stain for light microscopic observation.

Histopathologically, tumor cells that had proliferated in the myxoedematous matrix (Figure 3A) consisted of two different types: a large portion comprised spindle cells, and polyhedral cells were also identified as a minor component. Spindle cells had an elongated, blunt-ended and hyperchromatic nucleus plus spindle, were fibrillated and possessed an eosinophilic cytoplasm (Figure 3D and 4A). In contrast, polyhedral cells had a hyperchromatic and eccentric nucleus with a polyhedral, large, and eosinophilic cytoplasm (Figure 5A). Spindle cells showed twelve mitoses per ten high-power fields. Accordingly, the histological grade of the tumor corresponded to grade-2 (tumor differentiation: score-2; mitotic counts: score-2; tumor necrosis: score-1) following to the French National Federation of Cancer Centers (FNCLCC) grading system (Figure 3C and 3D) [12].

Although a few polyhedral cells were confirmed, morphological findings on HE double stain indicated a myxoid type of leiomyosarcoma.

\section{Immunohistochemical findings}

Several kinds of monoclonal antibody were used to evaluate tumor cells immunohistochemically and included anti-Vimentin, CD31, CD34, cytokeratin (CK AE1/AE3, $34 \beta$-E 12, 5/6, and CAM 5.2), desmin, $\alpha$-smooth muscle actin ( $\alpha$-SMA), myoglobin, myogenin, and Ki-67 (MIB-1) antibodies. All tumor cells showed strong positive reactivity for vimentin and negative reactivity for CD31, CD34, and myoglobin (Figure 4D and 5D). Spindle cells showed focal positive reactivity for desmin, $\alpha$-SMA, and cytokeratin CAM 5.2 (Figure 4B, C, and $4 \mathrm{~F})$. In contrast, polyhedral cells showed positive reactivity for desmin, but negative reactivity for $\alpha$-SMA and cytokeratin CAM 5.2 (Figure 5B, C, and 5F). Ki-67 (MIB-1) labeling index in the spindle and polyhedral cells were estimated as $27.1 \%$ and $33.3 \%$, respectively. It is interesting to note that $2.1 \%$ of spindle cells and $23.1 \%$ of polyhedral cells showed positive reactivity for myogenin (Figure 4E and $5 \mathrm{E}$ ). Furthermore, to determine whether tumor cells are present as double positive
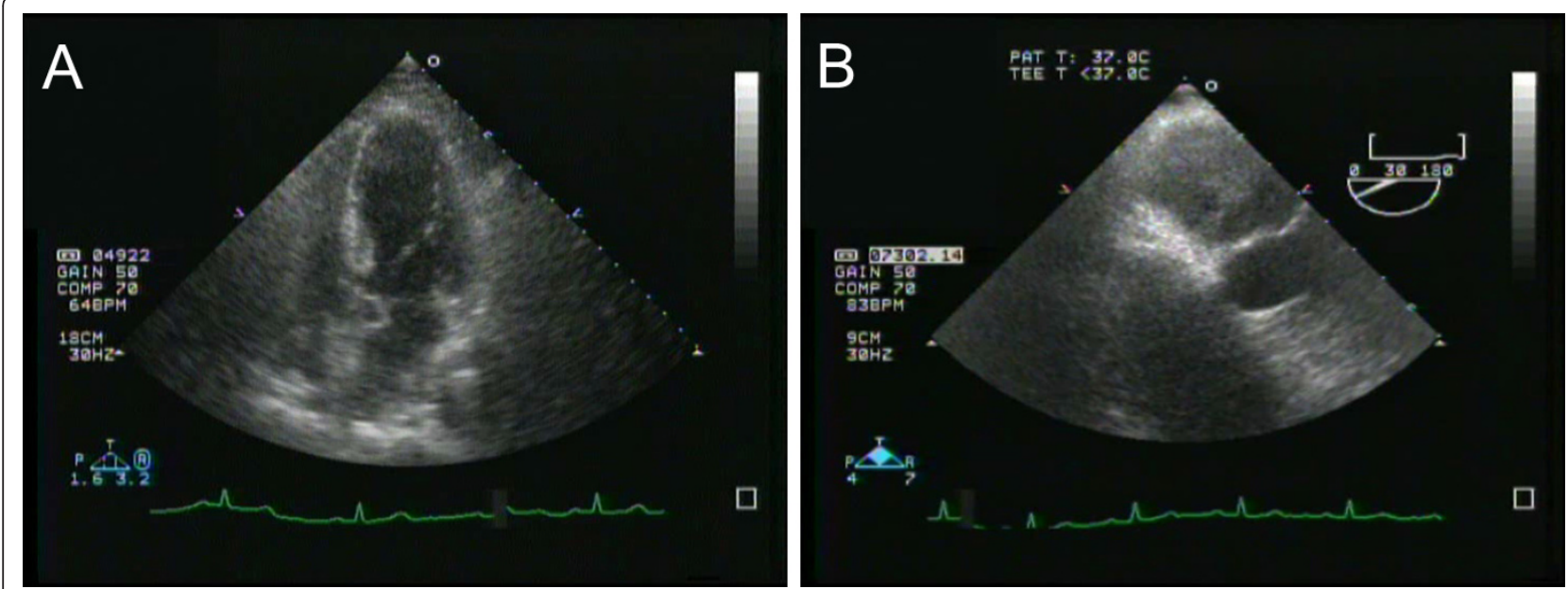

Figure 1 Photograph showing cardiac ultrasonography. (A) Transthoracic cardiac ultrasonography performed in our hospital showed showing a club -shaped tumor of $34 \mathrm{~mm}$ in diameter inside the left atrial cavity in a four-cavities tomogram. (B) Transesophageal cardiac ultrasonography showed showing a broad-based, gigantic, and multilocular tumor occupying almost the entire left atrium. 


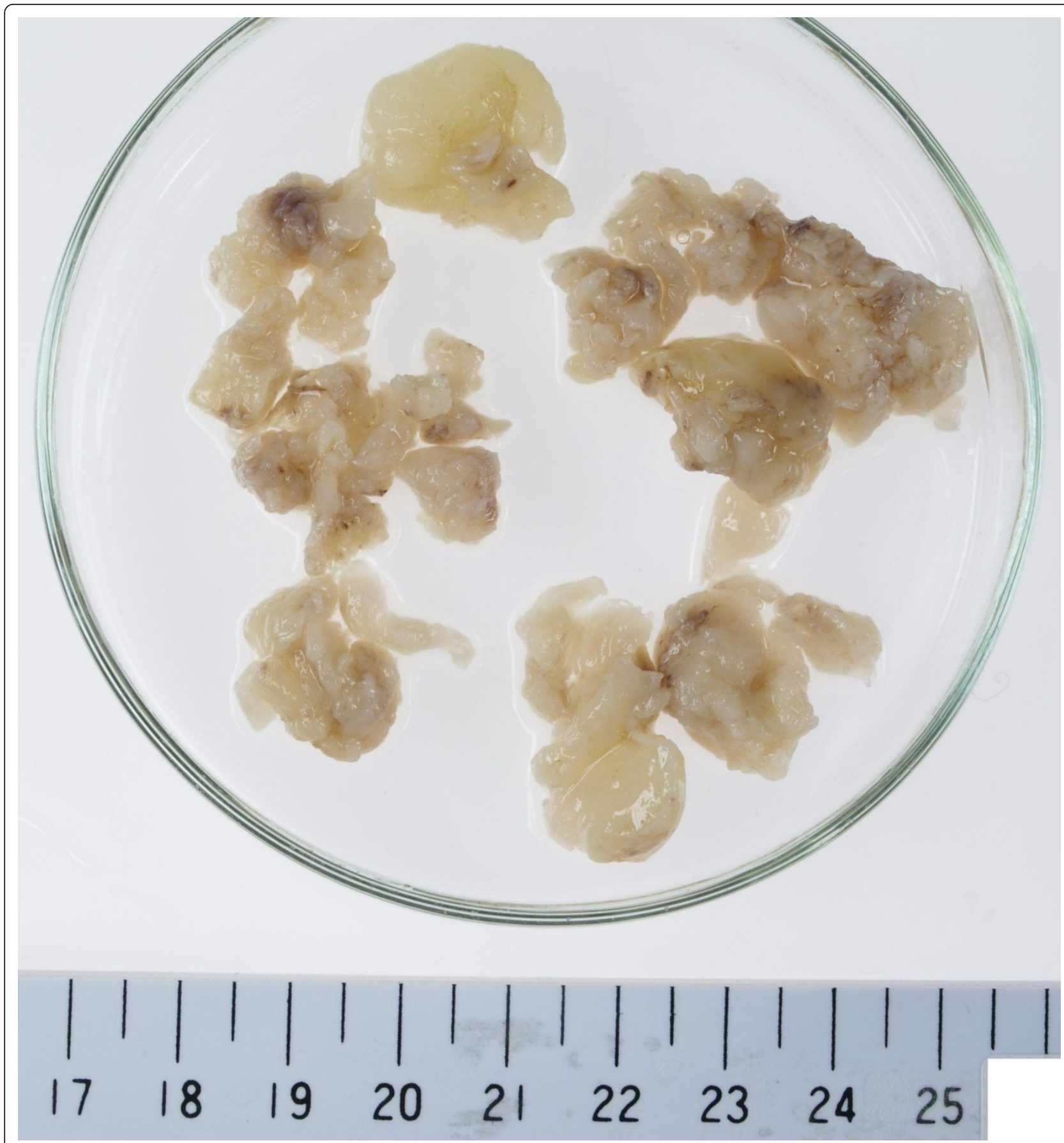

Figure 2 Photograph of the surgical specimen. The submitted specimen comprised several cakes of the tumor (measuring up to $41 \times 28 \times$ $14 \mathrm{~mm}$ in size) with a gray-white color on the surface.

for both $\alpha$-SMA and myogenin, and to ascertain the morphological characteristics of these tumor cells, we performed double-immunostaining for $\alpha$-SMA and myogenin. The rates of $\alpha$-SMA and myogenin double negative, $\alpha$-SMA single positive, myogenin single positive, and $\alpha$-SMA and myogenin double positive in spindle cells were estimated as $69.1 \%, 28.8 \%, 1.1 \%$, and $1.0 \%$, respectively (Figure 6A, B, C, and 6D). In contrast, the rates in polyhedral cells were estimated as $76.9 \%, 0.0 \%$, $23.1 \%$, and $0.0 \%$, respectively. These results are summarized in Table 1. According to the morphological and immunohistochemical findings, we diagnosed this primary cardiac tumor as a leiomyosarcoma with partial rhabdomyoblastic differentiation. 

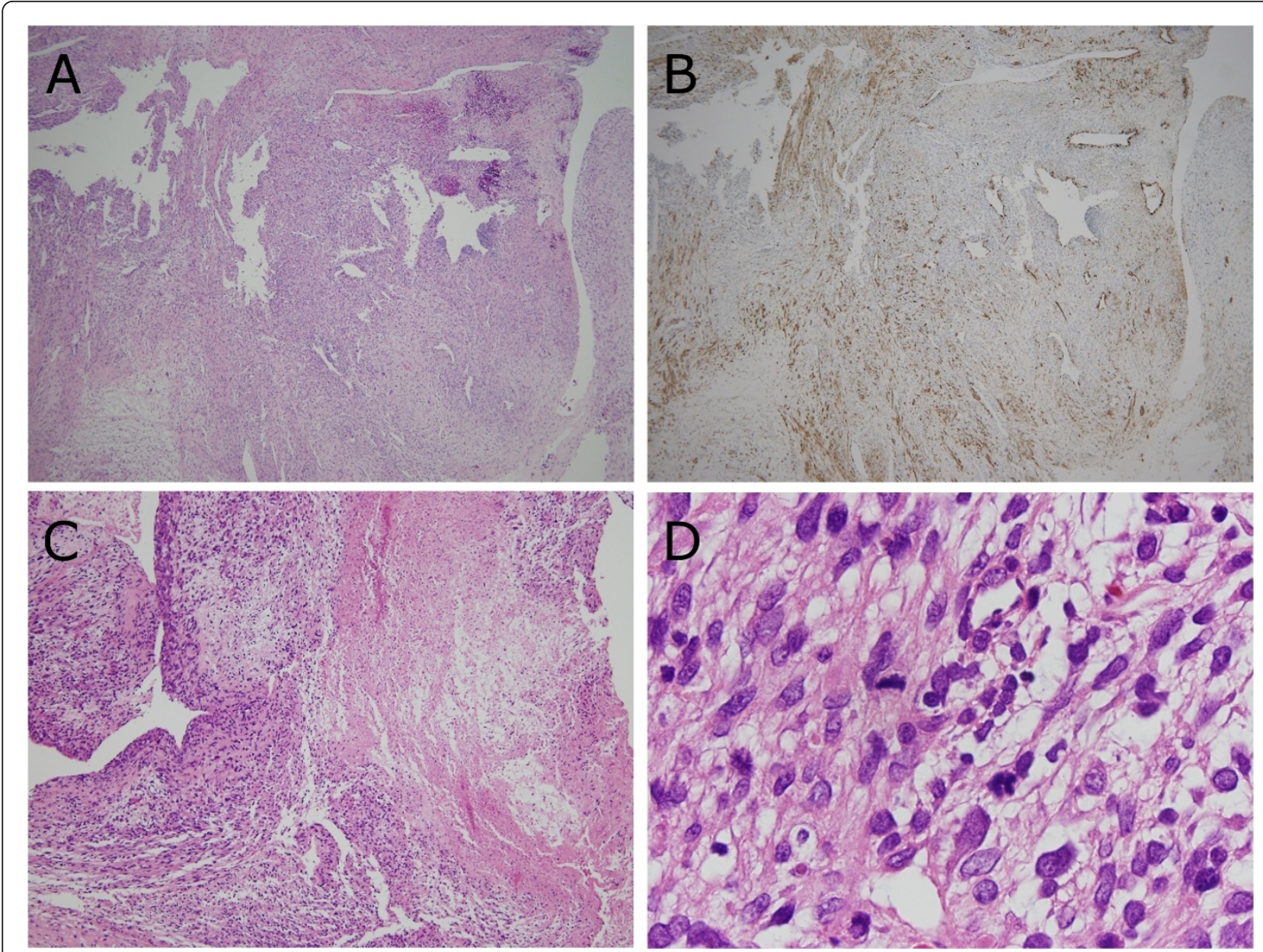

Figure 3 Photomicrographs showing spindle cells with areas of hypercellularity or necrosis. (A) Low-power view of the area with spindle cells proliferation (Hematoxylin and Eosin (HE) double stain, $\times 40$ ). (B) Spindle cells with positive reactivity for $\alpha$-smooth muscle actin (SMA) comprise approximately 30\% area of the tumor (Immunostain, anti- $\alpha$-SMA $\times 40$ ). (C) There is focus of necrosis in the limited the tumor.

Following to the French National Federation of Cancer grading system, presence of tumor necrosis less than half in area corresponds to score-1 (HE double stain, $\times 100$ ). (D) Spindle cells showed mitosis. On average, twelve mitoses per ten high-power fields were confirmed. Following to the French National Federation of Cancer grading system, mitotic activity of the present case corresponds to score-2 (HE double stain, $\times 1000)$.

\section{Discussion}

Leiomyosarcoma occurring as a primary cardiac tumor has been known as an extremely rare condition of which the rate represents less than $1 \%$ of all primary cardiac malignant tumors [2]. Furthermore, to the best of our knowledge there has been no report of a case of primary cardiac leiomyosarcoma with partial rhabdomyoblastic differentiation. In general, leiomyosarcoma is currently subdivided histologically into four types: classical, epithelioid, pleomorphic, and myxoid [13]. The morphological findings of the present case indicated a myxoid type of leiomyosarcoma, but immunohistochemistry revealed that a few tumor cells showed positive reactivity for myogenin. This has been known as a myogenic transcriptional regulatory protein which is expressed in the early phase of skeletal muscle differentiation (rhabdomyogenic differentiation), and it induces differentiation of myoblasts into the multinucleated myotube [14]. This myogenic regulatory protein has been largely accepted as a sensitive and specific immunohistochemical marker for rhabdomyosarcoma or other tumors with rhabdomyoblastic differentiation [14].

Meanwhile, it is interesting to note that the spindle cell showed positive reactivity for CK CAM 5.2. Although, it has been well known that leiomyosarcoma usually showed negative reactivity for epithelial markers [15], some investigators described that a part of leiomyosarcoma shows positive reactivity for CK [15-17]. Therefore, CK CAM 5.2 expression in the present case may support a diagnosis of leiomyosarcoma. However, to make diagnosis of leiomyosarcoma with rhabdomyoblastic differentiation, we should refer three important tumors and deny 

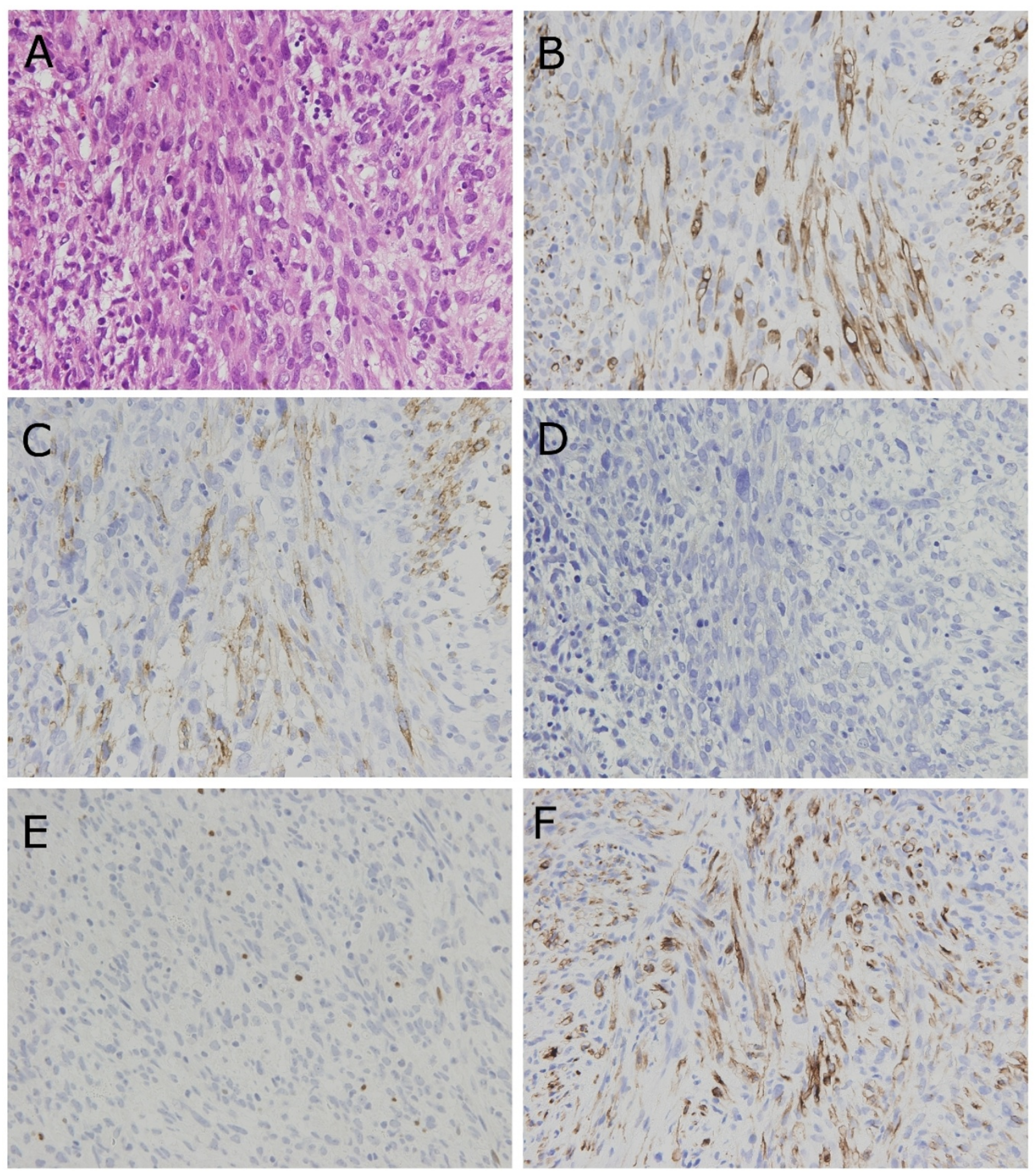

Figure 4 Photomicrographs showing spindle cells and their phenotypical expression. (A) Spindle cells had an elongated, blunt-ended and hyperchromatic nucleus plus spindle, were fibrillated, and possessed an eosinophilic cytoplasm. Occasional cells have perinuclear vacuoles (Hematoxylin and Eosin double stain, $\times 400$ ). (B, C, D, E, and F) Photomicrographs of immunostain with desmin (B), $\alpha$-smooth muscle actin (C), myoglobin (D), myogenin (E), and cytokeratin CAM $5.2(F)$, respectively $(\times 400)$.

them, respectively, which comprise undifferentiated pleomorphic sarcoma (UPS), rhabdomyosarcoma, and rhabdomyoma. Cardiac UPS usually occurring at the left atrium, histopathologically comprises a mixture of spindle cells in a storiform pattern with polyhedral cells [5].
Furthermore, high-grade undifferentiated sarcomas can exhibit focal $\alpha$-SMA expression [15]. These findings are similar to the present case. However, the spindle cell, a major component of the present tumor, had an elongated, blunt-ended, and hyperchromatic nucleus plus 

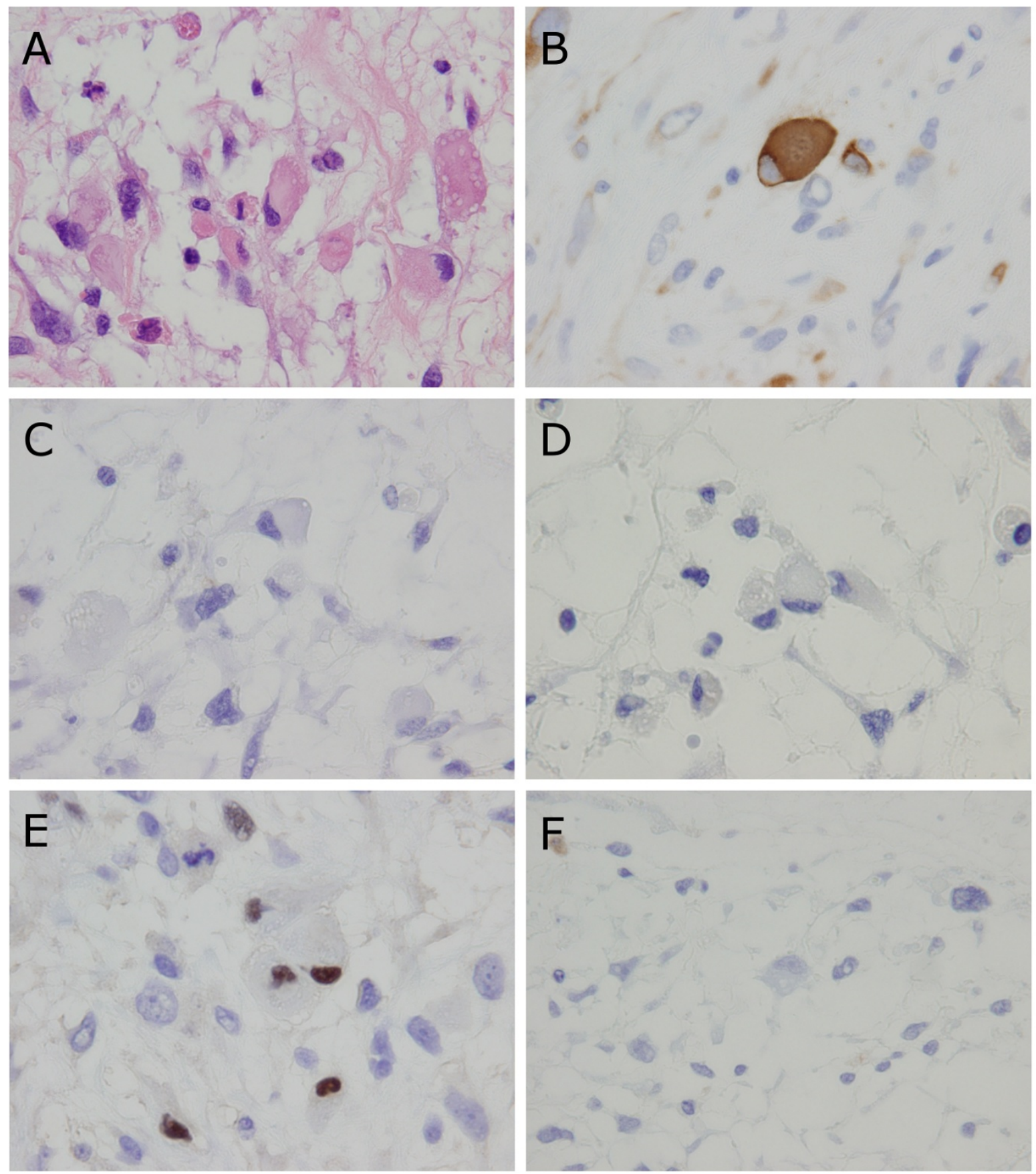

Figure 5 Photomicrographs showing polyhedral cells and their phenotypical expression. (A) Polyhedral cells had a hyperchromatic and eccentric nucleus with a polyhedral, large, and eosinophilic cytoplasm (Hematoxylin and Eosin double stain, $\times 1000)$. (B, C, D, E, and F) Photomicrographs of immunostain with desmin (B), $\alpha$-smooth muscle actin (C), myoglobin (D), myogenin (E), and cytokeratin CAM 5.2 (F), respectively $(\times 1,000)$.

spindle, fibrillated, and eosinophilic cytoplasm. In addition, the cell showed positive reactivity both for $\alpha$-SMA and desmin, focally, by immunohistochemical examination. These findings allowed disclosing the smooth muscle differentiation. Furthermore, some of the spindle cell also showed positive reactivity for CK CAM 5.2, of which positive ratio has been reported ranging from $22.2 \%(2 / 9)$ to $35.0 \%(14 / 40)$ in leiomyosarcoma [16,17]. Although it still remains a difficulty for decision, we made the diagnosis of leiomyosarcoma rather than UPS. On the other 

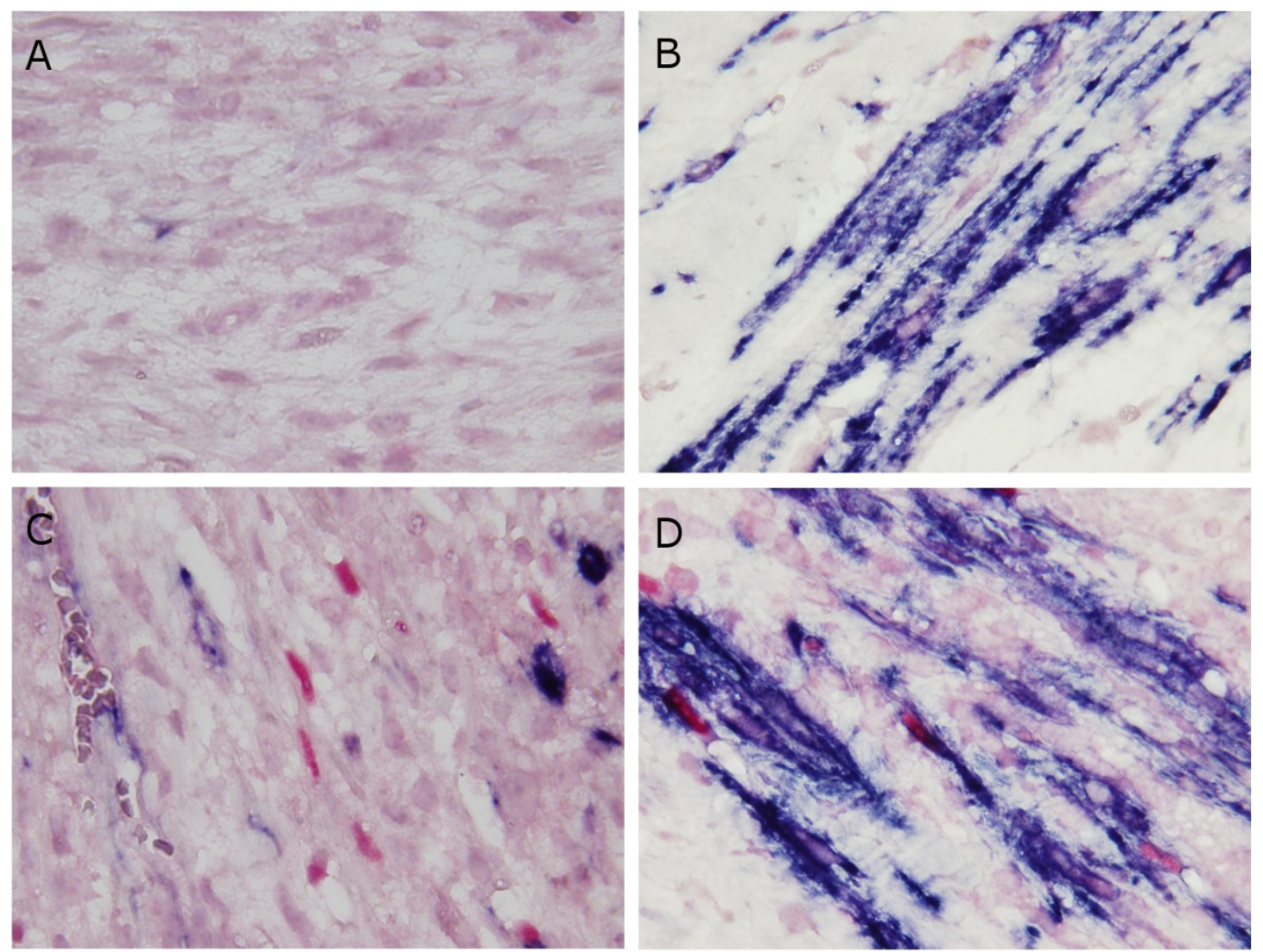

Figure 6 Photomicrograph showing the results of double-immunostaining of spindle cells. Positive reactivity for $\alpha$-smooth muscle actin (SMA) is recognized as a blue immunohistochemical signal in the cytoplasm, and for myogenin is recognized as a red immunohistochemical signal in the nucleus. (A) Negative reactivity for both $\alpha$-SMA and myogenin $(\times 1000)$. (B) Positive reactivity for $\alpha$-SMA alone $(\times 1000)$. (C) Positive reactivity for myogenin alone $(\times 1000)$. (D) Positive reactivity for both $\alpha$-SMA and myogenin $(\times 1000)$.

hand, since rhabdomyosarcoma has been know as the second most common primary cardiac malignant tumor [2], that should also be considered as a disease for differential diagnosis. Especially, embryonal rhabdomyosarcoma usually shows similar morphologic findings of the

Table 1 Summary of phenotypical expression by immunohistochemical examination

\begin{tabular}{|c|c|c|}
\hline & Spindle cell & Polyhedral cell \\
\hline $\begin{array}{l}\alpha-S M A \text { and myogenin double negative } \\
\alpha-S M A(-) \text { and myogenin (-) }\end{array}$ & $69.1 \%$ & $76.9 \%$ \\
\hline $\begin{array}{l}\alpha \text {-SMA single positive } \\
\alpha \text {-SMA (+) and myogenin (-) }\end{array}$ & $28.8 \%$ & $0.0 \%$ \\
\hline $\begin{array}{l}\text { myogenin single positive } \\
\alpha-\text { SMA }(-) \text { and myogenin }(+)\end{array}$ & $1.1 \%$ & $23.1 \%$ \\
\hline $\begin{array}{l}\alpha \text {-SMA and myogenin double positive } \\
\alpha \text {-SMA }(+) \text { and myogenin }(+)\end{array}$ & $1.0 \%$ & $0.0 \%$ \\
\hline
\end{tabular}

SMA: smooth muscle actin.

The rates of $\alpha$-SMA and myogenin double negative, $\alpha$-SMA single positive, myogenin single positive, and $\alpha$-SMA and myogenin double positive in spindle cells were estimated as $69.1 \%, 28.8 \%, 1.1 \%$ and $1.0 \%$, respectively. present case, such as varying degrees of cellularity containing hypercellular and loosely textured myxoid areas, hyperchromatic and round or spindle-shaped nucleus, and eosinophilic cytoplasm [18]. However, embryonal rhabdomyosarcoma is uncommon in patients older than 40 years of age [18] and neither cross-striation nor myoglobin expression was proven in the present case. Furthermore, a large body of spindle cells showed negative reactivity for myogenin (only $2.1 \%$ of them showed positive reactivity) that has been largely accepted as a sensitive and specific immunohistochemical marker for rhabdomyosarcoma or other tumors with rhabdomyoblastic differentiation [14]. According to our immunohistochemical examinations, we were able to deny typical rhabdomyosarcoma. As for rhabdomyoma, the most common subtype of cardiac origin has been known as cardiac rhabdomyoma, but it occurs almost exclusively in the hearts of infants and young children and composes predominantly large polygonal vacuolated spider cells [19]. Therefore, the adult type of rhabdomyoma should 
be considered as differential diagnosis which is usually composed of tightly polygonal cells which had peripherally placed nucleus plus acidophilic, finely granular, and vacuolated cytoplasm. However, mitotic figures are nearly absent, cross-striations can be discerned, and show positive reactivity for rhabdomyogenic markers immunohistochemically in these two subtypes of rhabdomyoma [19]. These results were different from the findings extracted from the present case.

On the other hand, only one case of sarcoma arisen from myocardium with rhabdomyoblastic differentiation has been reported by Kabir et al. [20] who described a malignant peripheral nerve sheath tumor indicated an area of rhabdomyoblastic differentiation in part. In their report, a little information of immunohistochemical examinations was described which simply comprised positive reactivity for $\mathrm{s}-100$ protein and focal for desmin. These results were different from these of the present case, but comparative discussion could not be completed in detail. Therefore, we preferred to diagnose this primary cardiac malignant tumor as a leiomyosarcoma with partial rhabdomyoblastic differentiation. Previous studies of leiomyosarcoma with rhabdomyoblastic differentiation have conducted to those arisen from another site, and Oshiro et al. have reported that leiomyosarcoma with rhabdomyoblastic differentiation shows poorer prognosis than typical leiomyosarcoma [6]. In fact, the present case showed rapid growth of the tumor and the patient died due to extensive metastases in the lungs despite early diagnosis and surgical removal. Table 2 presented herein summarizes major clinical data of nineteen cases of leiomyosarcoma in soft tissue with rhabdomyoblastic differentiation, and includes the present case representing the first report of leiomyosarcoma arising from the myocardium [table 2]. The patient age ranged from 33 to 85 (mean: 62.7). The male-to-female ratio was 10:10. The tumor sizes ranged from 20 to $250 \mathrm{~mm}$ (mean: 116.4).

We wish to take a more detailed discussion on the present case, especially in relation to tumor cell differentiation with phenotypical expression analysis. The

Table 2 Literature summary of cases of leiomyosarcoma with rhabdomyoblastic differentiation

\begin{tabular}{|c|c|c|c|c|c|c|c|}
\hline Reference & Year & $\begin{array}{l}\text { Age } \\
\text { (years) }\end{array}$ & Sex & Site & $\begin{array}{l}\text { Size } \\
(\mathrm{mm})\end{array}$ & Operation and adjuvant therapy & Follow up \\
\hline Falconieri et al [3]. & 1996 & 83 & Female & Breast & 60 & Radical mastectomy & 10 mo NED \\
\hline Roncaroli et al [4]. & 1996 & 59 & Female & Retroperitoneum & 170 & Excision & 8 mo NED \\
\hline Leoong et al [5]. & 1996 & 56 & Male & Stomach & 60 & Partial gastrectomy & NR \\
\hline Oshiro et al [6]. & 2000 & 55 & Female & $\begin{array}{l}\text { Abdominal } \\
\text { cavity }\end{array}$ & 180 & Marginal excision & 85 mo NED \\
\hline Oshiro et al [6]. & 2000 & 62 & Female & Omentum & 130 & Marginal excision & NR \\
\hline Oshiro et al [6]. & 2000 & 53 & Female & Thigh, subcutis & 80 & Wide excision & 19 mo DOD \\
\hline Oshiro et al [6]. & 2000 & 76 & Male & Buttock, subcutis & 60 & Wide excision & 27 mo NED \\
\hline Oshiro et al [6]. & 2000 & 33 & Male & Thigh muscle & 60 & Wide excision & 45 mo DOD \\
\hline Oshiro et al [6]. & 2000 & 54 & Male & Thigh muscle & 220 & Wide excision and chemotherapy & Lung metastasis, 9 mo DOD \\
\hline Oshiro et al [6]. & 2000 & 84 & Male & Buttock & 30 & $\begin{array}{l}\text { Wide excision, radiation, and } \\
\text { chemotherapy }\end{array}$ & 93mo NED \\
\hline Oda et al [7]. & 2001 & 50 & Female & Back & NR & Excision & $6 \mathrm{mo} \mathrm{DOD}$ \\
\hline Oda et al [7]. & 2001 & 60 & Male & Retroperitoneum & 140 & Excision & NR \\
\hline Oda et al [7]. & 2001 & 85 & Male & Buttock & 20 & Excision & $\begin{array}{l}5 \text { mo local recurrence (additional } \\
\text { wide excision), } 65 \text { mo NED }\end{array}$ \\
\hline Oda et al [7]. & 2001 & 33 & Male & Thigh & 60 & Wide excision and chemotherapy & Lung metastasis, 45 mo DOD \\
\hline Oda et al [7]. & 2001 & 76 & Male & Buttock & 60 & Excision & NR \\
\hline Levine et al [8]. & 2002 & 72 & Female & Uterus & 210 & $\begin{array}{l}\text { Hysterectomy with salpingo- } \\
\text { oophorectomy }\end{array}$ & 6 mo NED \\
\hline Shintaku et al [9]. & 2004 & 70 & Female & Uterus & 250 & $\begin{array}{l}\text { Hysterectomy with salpingo- } \\
\text { oophorectomy and chemotherapy }\end{array}$ & Liver metastasis, outcome was NR \\
\hline Nikaido et al [10]. & 2004 & 67 & Male & $\begin{array}{l}\text { Inferior vena } \\
\text { cava }\end{array}$ & 140 & Radical excision & Lung metastasis, 13 mo DOD \\
\hline Yorulmaz et al [11]. & 2007 & 56 & Female & Uterus & 240 & $\begin{array}{l}\text { Surgical removal, radiation, and } \\
\text { chemotherapy }\end{array}$ & $8 \mathrm{mo}$ DOD \\
\hline Present case & 2009 & 69 & Female & Heart & 41 & Surgical removal & Lung metastasis, 9 mo DOD \\
\hline
\end{tabular}

NR: not reported, DOD: died of disease, NED: no evidence of disease, mo: months.

There are twenty cases of leiomyosarcoma with rhabdoid differentiation including the present case. 
spindle cell, a major component of the tumor, has the potential to differentiate into a smooth muscle cell which can be phenotypically identified with positive reactivity for $\alpha$-SMA. However, we found $2.1 \%$ of spindle cells showed positive reactivity for myogenin, and half of myogenin-positive spindle cells showed positive reactivity for $\alpha$-SMA at the same time. In contrast, none of polyhedral cells showed positive reactivity for $\alpha$-SMA, but they exhibited a significantly higher myogenin-positive rate than spindle cells. These findings support the following hypothesis. First, the "rhabdomyoblastic differentiation" observed in the present case may represent the early stage of rhabdomyogenic differentiation because tumor cells showed positive reactivity for myogenin which has been known as a maker of cells in the early phase of rhabdomyogenic differentiation, and exhibited neither cross-striation nor myoglobin expression. Second, polyhedral cells may be in a more advanced stage of rhabdomyogenic differentiation than spindle cells because polyhedral cells were morphologically similar to rhabdomyoblasts and showed a significantly higher myogenin-positive rate than spindle cells.

Finally, the possibility of transdifferentiation or synchronous smooth and skeletal muscle differentiation in leiomyosarcoma was suggested in the present case because synchronous expression of $\alpha$-SMA and myogenin was confirmed in $1.0 \%$ of spindle cells. Overall, our immunohistochemical evaluation indicated that rhabdomyoblastic differentiation in leiomyosarcoma might be generated not only by de novo generation from mesenchymal cells.

\section{Conclusion}

We describe an extremely rare case of primary cardiac leiomyosarcoma with partial rhabdomyoblastic differentiation. The tumor indicated aggressive growth and the patient died despite early diagnosis and surgical removal. Furthermore, our immunohistochemical evaluation suggested that rhabdomyoblastic differentiation in leiomyosarcoma might be generated not only by de novo generation from mesenchymal cells. To the best of our knowledge, this is the first report of primary cardiac leiomyosarcoma with partial rhabdomyoblastic differentiation.

\section{Consent}

We could not get the proof of the patient's written and signed consent for the publication because we could not announce disease of our patient to herself due to her family's request. Furthermore, the patient has already died. However her family agreed our proposal using surgical specimen for our research and written informed consent was obtained from the patient's family (as a proxy) for publication of this case report and any accompanying images. A copy of the written consent is available for review by the Editor-in-Chief of this journal.

\section{Acknowledgements}

This work was supported by the Health Science Research Grants for Research on Emerging and Re-emerging Infectious Diseases (H16-Shinko-6, H19-Shinko-8, and H22-Shinko-8), Measures for Intractable Diseases (H20 nannchi ippann 35) from the Ministry of Health, Labor and Welfare of Japan, by a Grant of the Strategic Basis on Research Grounds for Nongovernmental Schools at Heisei 20th from the Ministry of Education, Culture, Sports, Science and Technology Japan to K. S, and Toho University project grant \#21-24 to Y. O. The authors thank Manabu Yamada, Rie Takahashi, Tadashi Ide, Tsutomu Hatori, Takayuki Hirano, and Kayoko Shimodaira for their excellent technical support or pathological advice.

\section{Author details}

'Department of Surgical Pathology, Toho University School of Medicine, 611-1 Omori-Nishi, Ota-Ku, Tokyo, 143-8541, Japan. ${ }^{2}$ Division of Cardiovascular Medicine, Department of Internal Medicine, Toho University Omori Medical Center, Toho University School of Medicine, 6-11-1 Omori-Nishi, Ota-Ku, Tokyo, 143-8541, Japan.

\section{Authors' contributions}

YO conceptualized the case report, integrated the data, and wrote the manuscript as a major contributor; KS carried out the histopathological evaluation and revised the manuscript; AN contributed to management of the patient and revised clinical description; KT contributed to management of the patient and gave final approval to the manuscript as a corresponding author; NK, TN, AM, and MW carried out the histopathologic evaluation and revised histopathological description; $\mathrm{MS}, \mathrm{NH}, \mathrm{KK}$, and IT carried out the histopathologic evaluation, JY contributed to management of the patient as a chief doctor of Division of Cardiovascular Medicine. All authors have read and approved the final manuscript.

\section{Competing interests}

Dr. Shibuya reports receiving research grants from Pfizer Japan Inc., Janssen Pharmaceutical K.K., and Dainippon Sumitomo Pharma Co. All authors declare that they have no competing interests.

Received: 5 October 2010 Accepted: 17 February 2011

Published: 17 February 2011

\section{References}

1. Shanmugam G: Primary cardiac sarcoma. Eur J Cardiothorac Surg 2006, 29:925-932.

2. Neragi-Miandoab S, Kim J, Vlahakes GJ: Malignant tumours of the heart: a review of tumour type, diagnosis and therapy. Clin Oncol (R Coll Radiol) 2007, 19:748-756.

3. Falconieri G, Della Libera D, Zanconati F, Bittesini L: Leiomyosarcoma of the female breast: report of two new cases and a review of the literature. Am J Clin Pathol 1997, 108:19-25.

4. Roncaroli F, Eusebi V: Rhabdomyoblastic differentiation in a leiomyosarcoma of the retroperitoneum. Hum Pathol 1996, 27:310-313.

5. Leong FJ, Leong AS: Malignant rhabdoid tumor in adults-heterogenous tumors with a unique morphological phenotype. Pathol Res Pract 1996, 192:796-807.

6. Oshiro Y, Shiratsuchi H, Oda Y, Toyoshima S, Tsuneyoshi M: Rhabdoid features in leiomyosarcoma of soft tissue: with special reference to aggressive behavior. Mod Pathol 2000, 13:1211-1218.

7. Oda Y, Miyajima K, Kawaguchi K, Tamiya S, Oshiro Y, Hachitanda Y, Oya M, Iwamoto Y, Tsuneyoshi M: Pleomorphic leiomyosarcoma: clinicopathologic and immunohistochemical study with special emphasis on its distinction from ordinary leiomyosarcoma and malignant fibrous histiocytoma. Am J Surg Pathol 2001, 25:1030-1038.

8. Levine PH, Mittal K: Rhabdoid epithelioid leiomyosarcoma of the uterine corpus: a case report and literature review. Int J Surg Pathol 2002, 10:231-236. 
9. Shintaku M, Sekiyama K: Leiomyosarcoma of the uterus with focal rhabdomyosarcomatous differentiation. Int I Gynecol Pathol 2004, 23:188-192

10. Nikaido T, Endo Y, Nimura S, Ishikura H, Ushigome S: Dumbbell-shaped leiomyosarcoma of the inferior vena cava with foci of rhabdoid changes and osteoclast-type giant cells. Pathol Int 2004, 54:256-260.

11. Yorulmaz G, Erdogan G, Pestereli HE, Savas B, Karaveli FS: Epithelioid leiomyosarcoma with rhabdoid features. Wien Klin Wochenschr 2007, 119:557-560.

12. Guillou L, Coindre JM, Bonichon F, Nguyen BB, Terrier P, Collin F, Vilain MO, Mandard AM, Le Doussal V, Leroux A, Jacquemier J, Duplay H, Sastre-

Garau X, Costa J: Comparative study of the National Cancer Institute and French Federation of Cancer Centers Sarcoma Group grading systems in a population of 410 adult patients with soft tissue sarcoma. J Clin Oncol 1997, 15:350-362.

13. Miyajima K, Oda Y, Tamiya S, Shimizu K, Hachitanda Y, Tsuneyoshi M: Cytogenetic and clinicopathological analysis of soft-tissue leiomyosarcomas. Pathol Int 2003, 53:163-168.

14. Folpe AL: MyoD1 and myogenin expression in human neoplasia: a review and update. Adv Anat Pathol 2002, 9:198-203.

15. Orlandi A, Ferlosio A, Roselli M, Chiariello L, Spagnoli LG: Cardiac sarcomas: an update. J Thorac Oncol 2010, 5:1483-1489.

16. Oliva E, Young RH, Amin MB, Clement PB: An immunohistochemical analysis of endometrial stromal and smooth muscle tumors of the uterus: a study of 54 cases emphasizing the importance of using a panel because of overlap in immunoreactivity for individual antibodies. Am J Surg Pathol 2002, 26:403-412.

17. Chu PG, Weiss LM: Keratin expression in human tissues and neoplasms. Histopathology 2002, 40:403-439.

18. Weiss SW, Goldblum JR: Rhabdomyosarcoma. In Enzinger and Weiss's Soft Tissue Tumors. 5 edition. Edited by: Weiss SW, Goldblum JR. St. Louis: MOSBY; 2007:599-607.

19. Weiss SW, Goldblum JR: Rhabdomyoma. In Enzinger and Weiss's Soft Tissue Tumors. 5 edition. Edited by: Weiss SW, Goldblum JR. St. Louis: MOSBY; 2007:584-588

20. Kabir S, Kapetanakis El, Shabbo F: Intracardiac malignant Triton tumor: a first presentation. Ann Thorac Surg 2010, 89:968-969.

\section{Pre-publication history}

The pre-publication history for this paper can be accessed here: http://www.biomedcentral.com/1471-2407/11/76/prepub

doi:10.1186/1471-2407-11-76

Cite this article as: Okubo et al.: Leiomyosarcoma with partial rhabdomyoblastic differentiation: First case report of primary cardiac origin. BMC Cancer 2011 11:76.

\section{Submit your next manuscript to BioMed Central and take full advantage of:}

- Convenient online submission

- Thorough peer review

- No space constraints or color figure charges

- Immediate publication on acceptance

- Inclusion in PubMed, CAS, Scopus and Google Scholar

- Research which is freely available for redistribution

Submit your manuscript at www.biomedcentral.com/submit
Biomed Central 